\title{
FUNCTIONAL TESTS OF THE KIDNEY IN UREMIA *
}

\author{
NELLIS B. FOSTER, M.D. \\ NEW YORK
}

In any disease in which the diagnosis cannot be reduced to something like certainty, the prognosis must evidently be considered with some reservation. If in addition diagnosis and prognosis are alike made dependent on laboratory tests, either these procedures must be of demonstrated accuracy and especial relevance or else we shall be led into blunders in diagnosis or faulty deductions in our conceptions of the nature of the disorder.

In relation to uremia, I wish to call attention to certain limitations of laboratory aids, and to exceptions which many cases present to what is perhaps a doubtful average, since by constancy of iteration some of these tests bid fair to be accepted as criteria.

Now, in the conditions we call uremia the clinical manifestations cover a wide range, and in proportion as the picture is varied and changeable the difficulties of correct interpretation are increased. It is just because there is no definite symptom-complex, no fixed association of physical signs correlated with uremia, that its recognition is often held to be simple, and yet the necropsy fails to confirm the diagnosis. In the absence of a more clearly defined clinical entity during life we must depend ultimately for the criterion on the anatomical changes found by the pathologist after death. The only exception, possibly, should be in those cases that have been under observation for long periods before the advent of uremia and in which this state is the logical culmination of events.

The cause of uremia is not known, but the common conception relates the condition to nephritis; whether by functional failure of the kidneys or otherwise, does not at present matter. At necropsy marked renal degeneration is requisite for confirmation of the diagnosis, and with this usually is found edema of the brain and often colitis. Since it is the conception of uremia that it is intimately related to severe nephritis and represents the denouement of a pathological process dependent on renal disease, or of which renal disease is an invariable accompaniment, it follows that the value of a test having for its aim the estimation of renal function, can be measured by the results elicited in demonstrated cases

* Submitted for publication July 16, 1913.

* From the First Medical Division New York Hospital and Department of Medicine, Cornell University. 
of uremia. If this assertion be not correct the only alternative is that uremia is not necessarily related to renal function.

The functional test for the kidneys that is being most generally employed by both internists and surgeons in America is that of phenolsulphonephthalein. In many cases of uremia the results secured by this test accord with the clinical data secured by other procedures. Cases of uremia often fail to eliminate in two hours enough of the substance to permit of quantitative estimation, and such patients sometimes die, sometimes improve sufficiently to leave the hospital. But there are notable exceptions in the operation of the test to which $\mathrm{I}$ wish to call special attention.

I shall cite but three cases representing three different types of nephritis.

C.ASE 1.-E. P. aged 53, was refused life insurance in 1909 in consequence of which he came to his physician; examination revealed moderate secondary anemia, cardiac hypertrophy without valvular disease, blood-pressure 190, arteriosclerosis and enlarged liver. The urine was increased in amount; nycturia was present. In a twenty-four-hour specimen, 2,300 c.c., there was albumen, $1+$ grams per liter, many granular casts and leukocytes. Diagnosis, secondary contracted kidney. In November, 1911, marked albuminuric retinitis developed. During December diarrhea was an obstinate symptom. The phenolsulphonephthalein test resulted in 53 per cent. being recovered in two hours. During Tanuary marked improvement took place. Another phenolsulphonephthalein test showed 55 per cent. recovery. There was apparently gradual improvement till the middle of February, when after one day of headache the patient had a severe convulsion; coma supervened and continued till death, thirty hours later. Postmortem: Anatomical diagnosis, chronic nephritis (red granular kidney), cardiac hypertrophy and dilatation, pulmonary edema, cerebral edema.

CASE 2.-C. H., aged 46, was admitted to hospital four days before death com plaining of extreme vertigo and cramps in the legs. On admission the patient was drowsy and in twenty-four hours there was coma. Examination was negative except for retinal hemorrhages; heart not hypertrophied; blood-pressure 130; respiration normal in character and rate; incontinence of urine; cathaterized specimen contained a trace of albumin and an enormous number of casts. Phenol. sulphonephthalein test gave 63 per cent. recovery in two hours. Clinical Diag. nosis: Chronic interstitial nephritis, uremia. Anatomical Diagnosis: Chronic nephritis, small granular kidney, cardiac dilatation, ulcerative colitis, edema of brain.

CASE 3.-B. F., aged 33. For a month there had been inereasing dyspnea and swelling of abdomen and ankles. Examination showed moderate general anasarca, some fluid in abdomen and both pleural cavities. Heart normal, bloodpressure average, 98 millimeters of mercury. Retinae normal. Urine: Average twenty-four voidings 1,100 c.c. Albumin constantly over 2 per cent.; many granular casts; some red blood-cells; chlorids diminished. Clinical Diagnosis: Parenchymatous nephritis.

The course of the disease appeared favorable, as the edema subsided rapidly, several phenolsulphonephthalein tests were done along with other tests; the last, eleven days before death, showed a recovery of 57 per cent. in two hours. Without prodromal symptoms other than slight nausea this patient had a severe convulsive seizure lasting nearly an hour and died shortly after. Anatomical Diagnosis: Chronic parenchymatous nephritis; large white kidney; cerebral edema; edema of lungs. 
These cases represent the types of renal lesion that we most often meet. The diagnosis was made correctly in each instance and was proved by necropsy. The phenolsulphonephthalein test gave a figure approximating normal in all, yet, in view of the termination of each case, one would hardly venture to assert that the renal function was normal. As to prognosis, this test would have indicated that recovery was almost certain. Granting that in many cases, perhaps the majority, the results of this test harmonize with the clinical picture and the course of events, we must assuredly find out in what percentage of cases of renal disease we are apt to be misled before we can venture any opinion whatever as to the clinical value of the test either diagnostically or prognostically. Does not the record of the above-cited cases suggest that the excretion of phenolsulphonephthalein depends on some other factor (circulation?) than pure renal disease, which by its presence or absence determines the rate of secretion by the kidney? Non-protein nitrogen of the blood?

In the last few years there is notable in the literature, especially that of Germany, an ever-increasing insistence on the significance of the nonprotein nitrogen (residual, filtrate, incoagulable nitrogen) of the blood. It is to be recalled that this is no new method of studying nephritis, although our technic at present may be better than formerly. Bright's cases were investigated by Babbington. Von Jacksch, Hoppe-Seiler, and Ascoli made many determinations on all sorts of cases and came to various opinions. Here too we have to do with a factor of degree. When the non-protein nitrogen is so large, as in some cases up to 200 milligrams per 100 cubic centimeters of blood, the outcome for the patient is pretty definitely bad. But those figures even in uremia are not the rule, and it must also be definitely stated that it is not at all unusual to find the non-protein nitrogen within the normal variation in cases of chronic interstitial nephritis with high blood-pressure - the very type of case in which the method is supposed to be of greatest clinical significance.

The normal limits for the non-protein nitrogen of the blood are according to various authors between 20 and 40 milligrams per 100 cubic centimeters. For normal controls I have utilized cases in the surgical service such as fractures and hernias, in which there was no evidence of renal or cardiovascular disease. With these individuals the average nonprotein nitrogen is 32 to 33 milligrams in 100 cubic centimeters of blood, with 44 milligrams as a maximum. ${ }^{1}$ Strauss believes that in parenchymatous nephritis the non-protein nitrogen is usually low, which is probably correct in cases of purely tubular involvement in which the process has not been of long duration, but the non-protein nitrogen is

1. The average non-protein nitrogen in seventy-two cases of uremia in my series was $87 \mathrm{mg}$. per cent. 
occasionally low in cases of contracted kidney also. Figures under 40 milligrams in 100 cubic centimeters of blood in these cases with uremia are not very exceptional in my series.

One is then confronted not by a positive fact which excludes uremia, but by a negative observation to be interpreted along with other clinical data. No one has gone to such arbitrary extremes as Widal, ${ }^{2}$ who, in a recent publication classifies uremia according to retention theories: (1) Those patients who retain $\mathrm{NaCl}$ and develop edema (chlorurémique). (2) Those who show nitrogen retention; that is to say, have an increase in the non-protein nitrogen of the blood (azotémique). (3) A combination of the two above classes.

As to the type azotemique, it is set forth that when the non-protein nitrogen is 50 to 100 milligrams in 100 cubic centimeters of blood, the prognosis is not immediately fatal; above 100 milligrams, it is to be estimated in months and weeks. 'Then what is to be said of the following?

CAsE 4.-A. 'T., aged 54. Slowly failing health for several months; notable in loss of strength; rapid fatigue on exertion and slight dyspnea; no history of edema. Three days before admission to hospital, severe vertigo. For two days there was some headache and the patient felt very drowsy.

Examination showed retinal hemorrhages, very slight cardiac hypertrophy, blood-pressure 140 to 150 millimeters of mercury, urine 500 to 800 cubic centimeters for twenty-four hours with a trace of albumin and many casts. No edema or fluid in cavities. Non-protein nitrogen, 28 milligrams in 100 cubic centimeters of blood.

The drowsiness deepened into stupor and after two days, coma. Death occurred on the fifth day after admission. Clinical diagnosis, uremia. Anatomical diagnosis, chronic nephritis (extremely small granular kidneys), edema of brain, marked colitis, uremia.

In this case it is evident that had undue weight been given to the low non-protein nitrogen one would have been led to conclude that there was not a severe nephritis, and that the retinal condition was due to some intracranial disease. Moreover, after the diagnosis of uremia had been made the non-protein nitrogen would have pointed, according to Widal, to a favorable outcome.

Tests and methods of investigation such as those I have discussed are undoubtedly valuable. Correctly applied they stimulate interest and lead in the long run to broadened knowledge. But just so soon as such methods are regarded as ultimate criteria, we are led first into errors in diagnosis, and from that creep into narrowed medicine and false ideas as to the pathology of a disease entity.

515 Park Avenue.

2. Widal, Fernand: Le Mouvement Medical, 1913, i, 1. 